What effect would increased consumption have on British agriculture and on trade ?

What economic and financial measures are required to initiate and promote increased consumption?

There is obviously a wide field of inquiry in which different Government departments should co-operate. A halt should be called to planning according to preconceived theories. We need far more information than is available before any more marketing schemes affecting the food supply of the country are brought into being.

\title{
Obituary
}

\section{Sir John McLennan, K.B.E., F.R.S.}

$\mathrm{T}$ THE great Exhibition, held in 1851, resulted in a large profit which was well invested, and the income has for many years been awarded as scholarships to research students. The results prove that it was one of the best investments ever made. John Cunningham McLennan, among many other men ultimately distinguished in science, received such an award, and it enabled him to join the Cavendish Laboratory at Cambridge from his home in Ontario after his graduation at the University of Toronto. Under the guidance of Sir J. J. Thomson, the Cavendish was enjoying a burst of discovery in connexion with the electron and the ionisation of gases. Young McLennan quickly caught fire, and on his return to Toronto as a demonstrator in physics, at the age of thirty-two, he published a paper in the Transactions of the Royal Society $(195,1899)$ in which he proved that the ionisation of gases due to electrons in motion was similar in type to that due to Röntgen rays or the radiations from uranium.

At the same time that Rutherford and H. L. Cooke at MeGill were discovering the penetrating radiation, supposedly and mainly from the radioactive substances in the ground, McLennan and E. F. Burton were finding, independently, similar results at Toronto. The later expansion of this subject into cosmic radiation was not then suspected. McLennan also carried out many experiments on the 'natural ionisation' in closed vessels, tracing the effects to minute quantities of radioactive materials, such as polonium in the walls, or radon in the enclosed air. By exposing sealed ionisation electroscopes over the ice on Lake Ontario, he definitely proved that the penetrating radiation over land was greater than over water, and this showed that a large part of the penetrating radiation came from the radium which Lord Rayleigh proved to be widely distributed in small quantities throughout primary and secondary rocks and sediments.

With immense energy, McLennan worked with others to raise funds for building that great physical laboratory at the University of Toronto which now so happily bears his name. Moreover, he secured abundant equipment with excellent apparatus especially for spectroscopy. One of his early successes was the discovery of the single line spectra of zinc, cadmium and magnesium and the deduction of their ionisation potentials. This was a sequel to the work of Frank and Hertz, who had obtained the single line spectrum for mercury. Electrons projected with low voltages in a discharge tube will excite a single line, but at a higher critical voltage the usual many-lined spectra appear.

During the War, McLennan came to England and took an intensely active part in the research work of the Admiralty in connexion with the anti-submarine campaign. His view was that a professor was coequal in rank with an admiral, and he reported directly to the First Sea Lord. Thus, in certain magnetic work, he insisted on the speedy isolation of a submarine in a dock at Portsmouth with a view to a magnetic survey and the determination of its magnetic moment, hitherto an unknown quantity. At the same time, he organised the extraction of helium from natural gases near Calgary, and obtained a considerable quantity intended for airships and balloons, but actually used after the War for experimental purposes. During the greater part of 1919 he was scientific adviser to the Admiralty.

After the War, McLennan returned to Toronto and continued with enthusiasm and success his work on spectroscopy, for which he was awarded a Royal Medal of the Royal Society in 1927, and the following year he had the honour of giving the Bakerian Lecture to the Society on "The Aurora and its Spectrum". The brilliancy of the aurora is shown by the spectroscope to be due to nitrogen, and the lower limit of the height of the discharge has been proved by Størmer to be about eighty miles above the earth's surface. On any clear night it had been proved by Lord Rayleigh, Vegard and others that there is also present in the spectrum a notable green line (5377) the cause of which gave rise to much controversy. In the Bakerian Lecture (Proc. Roy. Soc., A, 120, 1928) MeLennan described how he and G. M. Shrum had proved in the laboratory that the green line was due to oxygen, suitably mixed with argon, which when in a metastable state, as Frank had shown in similar cases, is capable of transferring its energy to a different type of gas.

McLennan next determined with eharacteristic energy to instal at Toronto a eryogenic laboratory capable of liquefying air, hydrogen and helium. In this difficult undertaking he received advice and plans from Onnes at Loyden and financial support from the National Research Council of Canada, and 
the scheme was quickly brought to a successful issue, so that new avenues of research work were opened to his numerous students. The relations between supraconductivity and magnetism both in elements and alloys were investigated, and such work is continuing under the able guidance of E. F. Burton, who succeeded McLennan on his retirement three years ago.

Prof. H. E. Armstrong wrote to The Times on October 12: "In McLennan we lost no mere scientific worker, but a man of the most admirable social gifts, indeed a man to fall in love with. It was a sight for the gods to see him beam with enthusiasm and joy, in his Royal Institution lecture, at his helium super-cooled ring in which the current put into it in Leyden in the afternoon continued to circulate. He had nursed it over from Holland by air."

In the Proceedings of the Royal Society, McLennan wrote more than fifty papers, in forty of which his research students collaborated. Perhaps it would not be invidious to name those who contributed two or more papers-D. S. Ainslie, H. J. C. Ireton, H. Grayson-Smith, A. B. McLay, A. R. MeLeod, G. M. Shrum. All this work, carried out at high pressure, sometimes led to stress and strain, and McLennan was always impatient with fools-sometimes with others-and though he could not suffer them gladly, his kindly, friendly nature usually restored sunshine after storm. He was a man who thought, spoke, wrote and lectured very clearly, and he was insistent on essential things. He was of a composite nature, greatly preferring friendship, but quite ready for a fight, and he fought hard. In the autumn of life his character was gentler and more mellow, and he was spared its winter. To his many friends and students he showed, time and again, the most thoughtful, unwearying kindness. A great factor in his life was the wise help and comfort of his able and interesting wife Elsie Monro, eldest daughter of William Ramsay, of Bowland, Scotland. Her death, two years ago, left him rather a desolate man, although he wore a brave face.

Of his work in England since his retirement Lord Rutherford writes of McLennan authoritatively : "Largely through his influence, the Union Minière of Brussels generously lent $5 \mathrm{gm}$. of radium to make a thorough investigation of the effects of mass radiation on cancerous growths. A committeo was formed to control this great experiment, presided over by the president of the Royal Society supported by the presidents of the Royal College of Physicians and Royal College of Surgeons, and representatives of the Medical Research Council and the Department of Scientific and Industrial Research. This work, which is still in progress, is being carried out at the Radium Institute. McLennan threw himself whole-heartedly into this new line of work, and personally supervised every detail of the scheme. He spent much of his time at the Institute, and characteristically established the friendliest relations not only with the staff but also with the patients under examination. His services to this investigation in radium beam therapy are indeed great, and his sudden removal is an irreparable loss. Warm-hearted and impulsive, his vitality, his boyish enthusiasm and transparent simplicity of nature, endeared him to all those who came closely into contact with him. His sudden end in the full tide of his activities is a great loss to science and humanity."

McLennan was born on April 14, 1867, and died of heart failure on his way from Paris to Calais on October 9, at the age of sixty-eight years. He received many and well-deserved honours. In 1924, he was president of the Royal Society of Canada and two years later was awarded the Flavelle Medal by that Society. He was elected a fellow of the Royal Society in 1915, and in the current year he received his knighthood.

A. S. EvE.

\section{Prof. Henry Briggs, O.B.E.}

Prof. Henry Brigas, who died in London on August 26 at the age of fifty-two years, had become, after a distinguished career, an authority on many subjects related to the scientific side of coal-mining. As head of the Department of Mining at Heriot-Watt College and Hood professor of mining at the University of Edinburgh, his influence amongst all students of mining technology was widely felt. In particular, mining engineers looked to Prof. Briggs for advice and information, based on his own original researches, on mine ventilation, on surveying and on the nature of coal. Latterly, he had interested himself in the subject of the production of oil from coal and carbonaceous materials, and had been appointed chairman of the Oil from Coal Committee of the Scottish National Development Council. He was a member of many scientific and technical societies, a member of council of the Institution of Mining Engineers and a fellow of the Royal Society of Edinburgh.

Briggs received his early education at Bradford whence, with a National Scholarship, he went to the Royal School of Mines and obtained the associateship with honours. He received his practical training in mining at collieries in Yorkshire, Cumberland and Wales and, previous to his appointment (in 1919) to the chair of mining at Heriot-Watt College, was, successively, demonstrator at the Royal School of Mines (and research assistant to Sir Clement le Neve Foster) and lecturer in mining at the University of Birmingham. His earlier research work included studies of mine rescue apparatus, and he was the inventor of an oxygen-breathing apparatus; during the War he carried out a number of investigations for the Trench Warfare Committee.

All Briggs's work showed originality of outlook and clarity of thought, and all his writings, with which he took particular pains, were lucid and literary. He had a keen and somewhat mordant wit which rendered his participation in discussions of controversial subjects highly effective; albeit he was constructive in his criticism. The coal-mining industry will feel his loss.
R. V. WHEELER. 